Angela Ndalianis

\title{
'HAIL TO THE KING!' - THE RETURN OF DOOM
}

It was back in 1993 that the horror was unleashed in the form of the Doo M: EVIL UNLEASHED. Developed by the Texas-based company id Software, this computer game was to introduce radical innovations not only to the First-Person Shooter (FPS) genre, but also to the soft and hardware technology that drove gaming. In I994, the sequel DOOM 2: HELL ON EARTH was to push the envelope further still. Drawing upon the science fiction and horror conventions of cinematic examples like AL i E N (Ridley Scott, I979), AL I E N S (James Cameron, I986) and EVIL DEAD I I (Sam Raimi, I987), both Doo m games upped the ante in game culture by transferring experiences familiar to the horror and science fiction film spectator over to the gamer. Discussing Doo M's influences, Jay Wilbur, the then chief executive officer of id stated that id 'wanted to make an ALIEN-like game that captured the fast-paced action, brutality and fear of those movies', while also amplifying the action and horror with EVIL DEAD II, whose "chainsaws and shotguns are an unbeatable combination!'. It would not be an understatement to say that these two games are up there with the most popular and influential games in game history. Significantly, one of the concerns of the games' creators - John Carmack and John Romero - was to transfer the dread, suspense and terror that was familiar to film audiences into the game environment.

Fast forward to 2004: a new breed of game horror is born again in the form of the PC-game Dоом 3 (to be released in December 2004 on X-Box). Like its addictive predecessors, D о о 3 introduces an even greater 'filmic' quality to its game space and, yet again, a new standard of gaming aesthetics and technology is created. Todd Hollenshead, head of id Software has stated that

'D оом 3 is a video game experience unlike any before it... From the cinema quality visuals and the incredible 5.I sound, to the terrifying atmosphere and hyper-realistic environments, the whole game screams "interactive horror film". 2

In particular, the Dоом games typify a strong tendency amongst game developers towards fetishizing the film object, and what is perceived as the cinema's convincing illusion of 'realism'. But the cinema is by no means the only media 


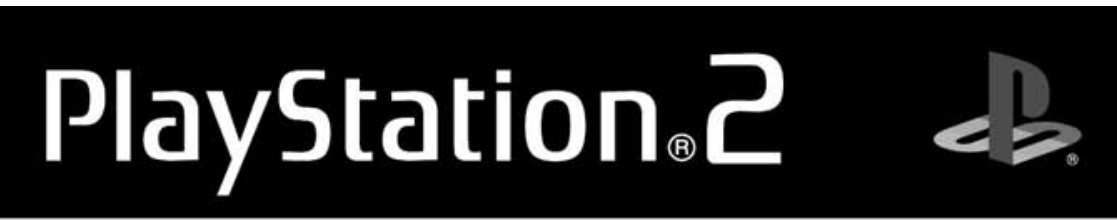

Packshot RESIDENT EVIL 3: OUTBREAK (Capcom, 2003)
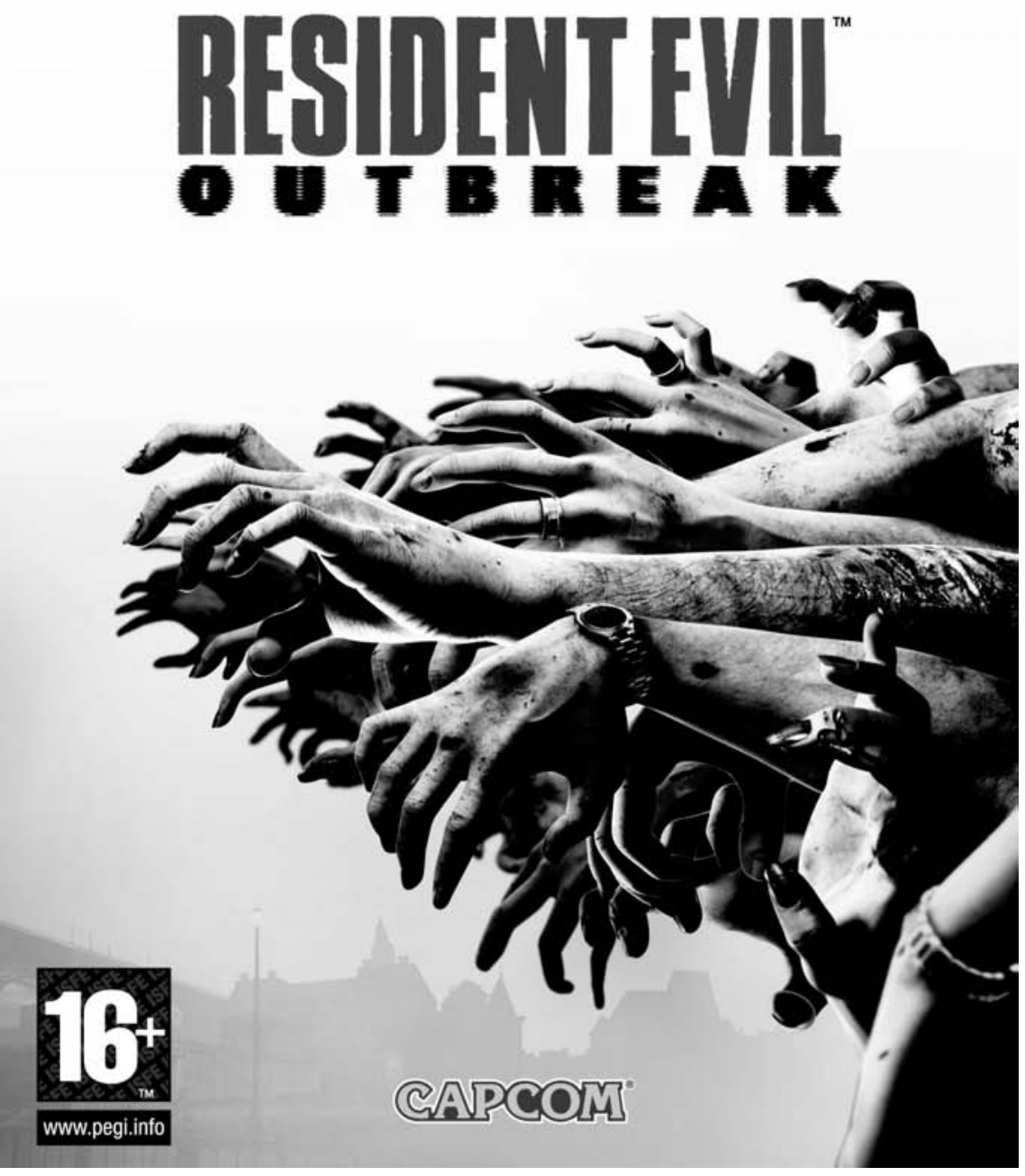

form that has impacted upon games. Through an analysis of D o o $\mathrm{M} 3$ and its heritage, this essay will address the question of games and their history, arguing that their reliance on past sources does not detract from their uniqueness. The creators of games like Dоом 3 deliberately place their creations within a rich, diverse tapestry of media history not in an admission of their lack of originality, but rather so that they can flag their innovation. In fact, as will be argued below, 
the ways in which John Carmack (Lead Programmer of the Dоoм trilogy) and the rest of the production team at id Software arrange and reshape their influences has a story to tell us about how these games situate themselves within the arena of competing entertainment media.

\section{'Nothing will come from nothing': revisiting the past}

By now, the basic premise of what Jay Bolter and Richard Grusin call remediation has been well rehearsed. ${ }^{3}$ Remediation involves the refashioning or assimilation of one or more media examples by another medium. In their own remediation of other media, the Dоом games reveal the complex relationships that currently exist across the entertainment industry. This cross-over, in turn, tests the clear separation between distinct media forms, and the overlap has ramifications for game analysis. While many game theorists and critics are still resistant to the idea that this new entertainment form, which is driven by new technology, can efficiently be understood in terms of other media influences (and their accompanying critical discourses), the reality is, to quote from William Shakespeare's King Lear, 'nothing will come from nothing'. Games do not emerge from a vacuum. Games possess a media history that includes an array of sources - films, comic books, painting, books, television, sports, music - in addition to examples from within their own medium. Computer games, like other entertainment forms, are reliant on a rampant hybridity and self-reflexivity. The RESI DENT EVI L (CAPCOM, I996-2004) games engage consciously with tropes from the George Romero 'living dead' films (NIGHT OF THE LIVING DEAD [I968], DAWN OF THE DEAD [I979] and DAY OF THE DEAD [I985]), the Italian zombie films DEMON (Lamberto Bava, I986) and DEMONs (Lamberto Bava, I986), as well as first and third person action and role playing games. MAX PAYNE 2: THE FALL OF MAX PAYNE (Remedy, 2003) also draws heavily on the cinema as a point of reference. In addition to film's stylistic properties (simulated camera movements, point-of-view shots, edits, and the bullet-time effect popularized in the MATRIX films [Wachowski Brothers, I999-2003]) the game is heavily steeped in the conventions of the detective and film noir genres. In the Playstation 2 game REz (Sonicteam/Sega, 200I), which was developed by Tetsuya Mizuguchi, the player adopts the role of a hacker who, flying through cyberspace, shoots at cyber-enemies. Remediating (by abstracting) the first person shooter, the destruction of the enemy produces patterns of sounds and effects, and the player becomes a composer of music and graphics on the fly. More interestingly, REz also remediates a 'high' art tradition. The audio-visual feast that is REz relies heavily on the paintings and theories of the early twentieth century artist Vassily Kandinsky. In his book Concerning the Spiritual in Art (I9I2) Kandinsky outlined his theories about the emotive and synaesthetic possibilities of colour: colour, he argued, could produce a musical effect. Through the double remediation of Kandinsky's abstract paintings and 


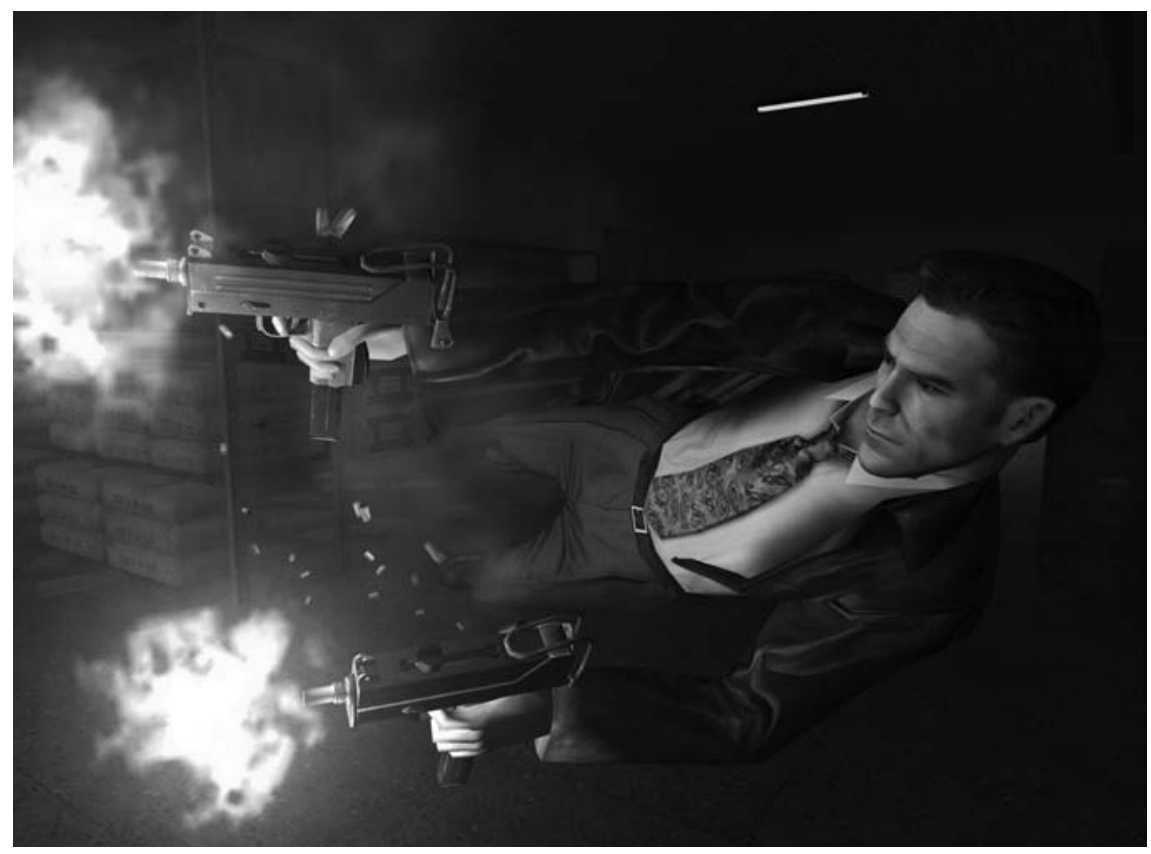

Screenshot from

MAX PAYNE 2:

THE FALL OF MAX PAYNE (Remedy, 2003)

Trance and Rave culture, REZ overloads the senses and bombards the player with psychedelic visuals and pulsating rhythms of colour and sound. Integral to such hybridization is the reality of history. The present turns to the past.

As I have argued elsewhere, ${ }^{4}$ media hybridisation is the product of and is crucial to the larger cross-over market that currently exists as a result of the conglomeration of the entertainment industry. It is a reality of commerce, which thrives on competition and diversification. ${ }^{5}$ The 'relationship between economics and aesthetics' has become crucial to the formal properties of entertainment media, but beyond that, as Justin Wyatt has so convincingly argued, economics gives rise to new aesthetics. ${ }^{6}$ This relationship suggests that the boundaries of our critical models must expand to consider cross-media hybrids. If we ignore media history, it will not magically go away. While the digital technology that drives games (and the responses it demands of its user) may be different to other media forms, it makes games no less susceptible to outside influences. As Bolter and Grusin explain, 'No medium today, and certainly no single media event, seems to do its cultural work in isolation from other media, any more than it works in isolation from other social and economic forces. What is new about new media comes from the particular ways in which they refashion older media and the ways in which older media refashion themselves to answer the challenges of new media'?

Significantly, it is in the process of highlighting the range of their external sources - their process of remediation - that games like MAX PAYNE 2, REZ and Dо о 3 also insist on their difference - or, rather, their uniqueness. The assertion of their originality remains paramount. In accumulating past references, 


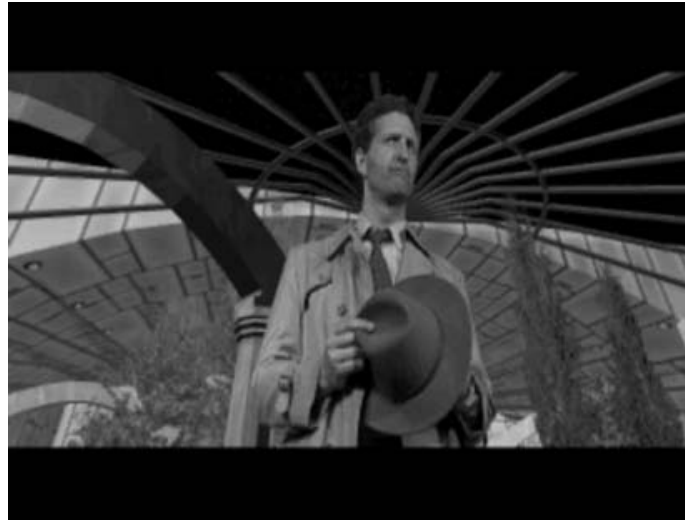

Screenshot from UNDER A KILLING MOON (Access Software, 1994) styles or allusions, these games are both acquiring their history but also placing themselves reflexively within the context of that history. In adapting forms of the past and present, games often attempt to convince the player that they are transforming their sources into a more 'authentic' experience. A playful discourse with the player results, one that requires that the player remains aware of the origins of the borrowings. The active and reflexive engagement of game players involves a critical understanding of the process of meaning production that is almost as integral as the game play.

MAX PAYNE 2, for example, begins its introduction by adapting the form of the graphic novel into its structure - complete with comic book frames and voice bubbles. But this source is also altered through the addition of the sounds of narration. The game then progresses into film language that includes mimicking camera movements, edits, genres, character types from the cinema - so the addition of motion and 3D is introduced to the previously static image. Then comes the third transition: to game play. The moving image, sound and narrative that we've just witnessed (and which we associate with the cinema) is suddenly made richer with the introduction of the player's ability to affect the actions seen on the screen. In addition, not only does MAX PAYNE 2 remediate the history of other media, it also refashions its predecessor MAX PAYNE (Remedy, 200I), replacing the more stony-faced Max with a digitally improved version that has more realistic surface texture and a wider range of facial expressions. Above all, such remediation demands attention from the player, attention that cries out 'Hey, look at me! I'm the new and improved revision'.

Or, to turn the clock back to I994 and the 'interactive movie' U N DE R A KILLING MOon (Access Software), again, the player is presented with an introduction that is sheer exhibitionism, one that claims CD-Rom gaming technology as superior to that which produced film classics. Game introductions have, especially since the mid-I990s, functioned as showcases of advances in game technology and aesthetics and, in keeping with this tradition, the introduction of UNDER A KILLING MOON presents a pure performance of digital spectacle. The cut-scene is used to exhibit the state of game technology in a highly exhibitionistic way. It knows its player is sitting in front of the computer screen marvelling at the illusions it conjures up. The introduction runs through a minihistory of classics of film history: the two spirit voices set against the backdrop of outerspace allude to the voices of the angels who discuss the fate of the main character in the I946 Frank Capra film IT'S A WON DERF U L LIFE; the documentary footage dealing with Hitler's involvement in the dark arts is stylistically pre- 
sented to refer to the 'News on the March' scene in Orson Welles' Citize $N$ KANE (I94I); the shift to the future sequence and the introduction of the detective - Tex Murphy - is an overt homage to Ridley Scott's I982 science fiction classic BLADE RUNNER. UNDER A KILLING MOON asks its player to acknowledge the influences that these paragons of the cinema have had on its own form, but it does this so that we may then recognize the new CD-Rom format (which was capable of more memory storage than previous PC-games) as the future of entertainment - the cinema's new competitor. This message is made loud and clear once the player shifts from the passive viewing required of the filminspired introduction to the game itself, which shifts the role of the viewer to that of player. As in the example of MAX PAYNE 2, through allusion, UNDER A KILLING MOON also posits a journey about technological evolution.

Discussing the rampant intertextuality that is typical of contemporary entertainment, Jim Collins perceptively observes that the result of such a complex web of intertextual references is, that narration is not simply limited to completing the plot, or to becoming involved in the 'syntagmatic axis of the narrative'. ${ }^{9}$ Instead, the 'layering of intertexts that occurs simultaneously informs those same topoi along a paradigmatic axis of antecedent representations' . ${ }^{\text {Io }}$ Therefore, story and action sequences that unravel during game play are not the only drive of these examples; allusions to (and the recognition of) other media that have impacted on games are just as integral to the player's involvement and interpretation. Beyond the gameplay, another game takes place: citation engages the player in a game that is about a homage to and renegotiation of the past of the cited sources. This 'hyperconsciousness' permits participants to become engrossed in the gameplay in a more conventional sense, with the story and themes unravelling along syntagmatic lines; but players are also encouraged to participate with the game on the paradigmatic level via the multi-layered, intertextual references. ${ }^{\text {II }}$ It is on this level that virtuosity comes into play.

\section{Style, transcendence and the DOOM palimpsest}

Like UNDER A KILLING MOON and MAX PAYNE 2, the DOOM games remain emblematic of this exhibitionist tendency in game culture. The game of virtuosity flaunts the ability of games to cannibalise older and more established cinematic (and other) rules (genres, narrative conventions, formal properties et cetera) and transform them into new formal and technological rules that bring with them accompanying new audience responses. Like its predecessors, Dо० M 3 is heavily steeped in the intertextual web of media history: media history external to the computer game medium but also from within it. What is especially striking about DOом 3 is that it continues a game of virtuosity that has been typical of id Software productions since the early I990s. In Dоo 3 the player adopts the role of a marine who reports for duty at a research installation on Mars. Soon af- 
Screenshot from роом 3 (id Software, 2004)

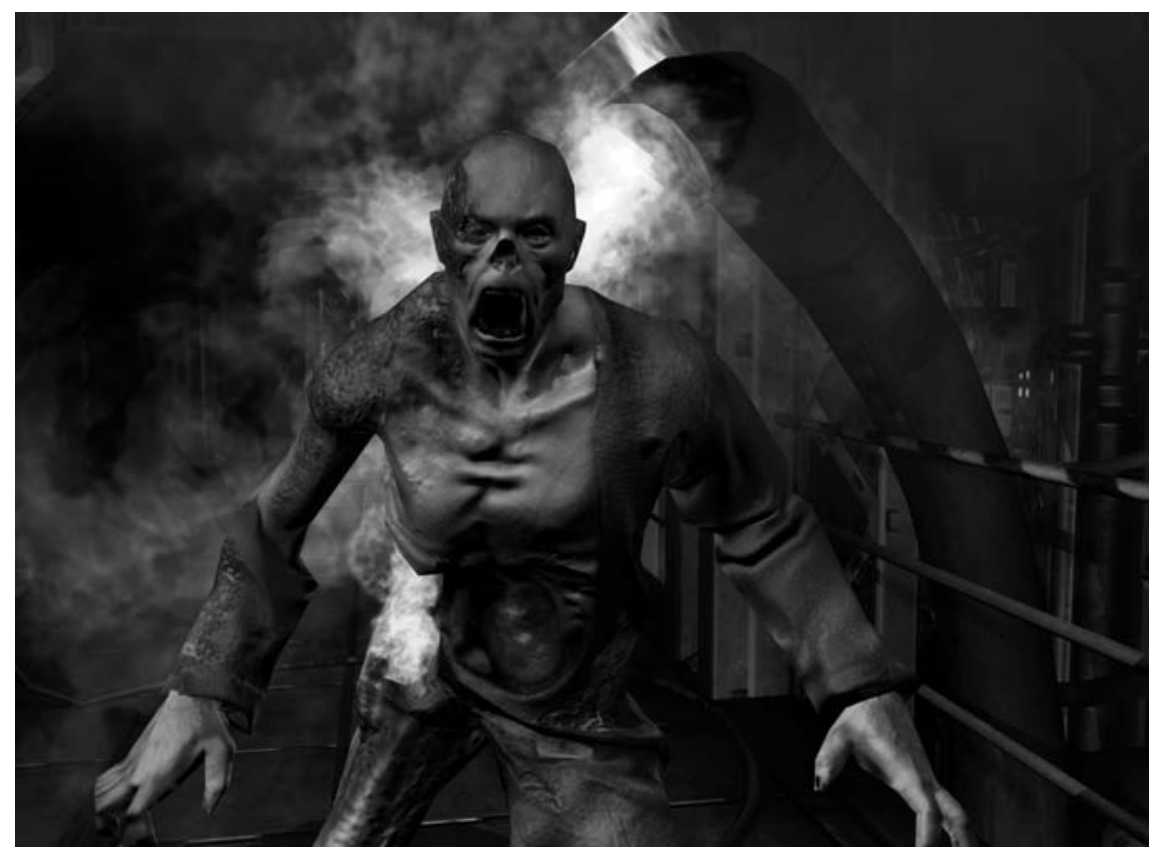

ter the marine's arrival, he meets the scientist he has been assigned to locate. True to the mad-scientist tradition of science fiction cinema, the scientist's unsanctioned experiments result in the opening of a portal to a hell dimension that launches a demon invasion on Mars. Hell itself is unleashed and the base's personnel are slowly transformed into zombie stalkers. The marine and player's mission is to close the portal and destroy all demons along the way - and there are many of them.

The visual references and themes of all three Doo $\mathrm{m}$ games oscillate across a variety of genres and media. The chainsaw weapon that the player has access to is a homage to the Ash character from the cult classic EV I L DEAD I I (who, in the film, maniacally chops off one of his appendages replacing it with a chainsaw). The player is thrust into science fiction environments that consist of moon bases, technological gadgets and teleporters as well as an oppressive atmosphere that recalls the ghoulish backdrops that dominate science fiction horror films like ALi En and ALi E N s. The spectres, imps, 'cacodemons', 'Hell knights', and 'Cyberdemons' not only allude to science fiction and horror film conventions, but the games also self-consciously rework the literary Lovecraftian Cthulhu Mythos, which has itself inspired an immense intertextual web of media examples. ${ }^{\text {I2 }}$ The creatures of Cthulu mythology, who once inhabited and ruled the Earth, 'are imprisoned or sleeping in various parts of the Earth and the galaxy, waiting for the time "when the stars are right" and they can reclaim their rule'. ${ }^{\text {I3 }}$ Like their demon cousins in the Do o M games, they can gain access to our world through portals that teleport them to various locations. In fact, Sandy 
Petersen, who created the hugely successful 'Call of Cthulhu' role-playing game, also worked with id Software on the роом games, and the equally successful id-produced QUAKE series (which included a creature taken directly from Cthulhu mythology - the Shub-Niggurath).

It is not due to a lack of creativity that роом 3 relies on these and other sources. Likewise, it is not a lack of creativity that underlies the return to the first роом. In returning to роом, доом 3 writes over its history, further layering the palimpsest that is роом culture. Taking a leaf out of the George Lucas book-of-STAR WARs-production history, id Software's Todd Hollenshead has stated that, in the production of роом 3 ,

'We pretend that роом and роом 2 didn't happen. Those games were massively successful in their own right so we had this great creative universe to draw upon, but really only the surface of it had been scratched because of the technological limitations of the time. ${ }^{\text {, }} 4$

Rather than wiping out history (an impossible task because роом I \& 2 are so deeply embedded in the psyche of gamer culture) what Dоом 3 does is to create a new layer over роом history. Like ruins and fragments, these entertainment forms evoke the existence of a past in the present while simultaneously transforming the ruin into a restored, majestic structure that operates like a richly layered palimpsest. The intensified self-consciousness that is typical of games like Dо० 3 is driven by virtuosity, the primary concern being to out-perform predecessors and contemporaries - to stamp its own identity across game history. According to Sypher a distinction needs to be made between style and stylization or technique. Style 'is based on the technique it transcends', ${ }^{15}$ and in this sense, роом 3 is brimming over with 'style'. Media conventions and past techniques are synthesized in order to transcend or perfect those techniques. Additionally, stylistic coherence is the result of the reorganization of past signs and stylizations into new combinations so that a discourse emerges between past and present.

However, it is not only external media that are assimilated and 'transcended'. Like its precursor Dоом 2, Dоом 3 revisits game history as well as the history of the роом series. While the gameplay is a straightforward shooter, it does introduce innovations to the thorny problem of story presentation within game space. The delivery of story to the player without awkward and prolonged interruptions of play has also greatly improved in Doo $\mathrm{M}$ 3. With the use of a personal P DA (Personal Digital Assistant) as well as those of discarded PDAS of dead prior owners, the plot slowly builds. Emails, personal notes, audio logs, video clips all add to the sense of mystery of and mastery over the story that unravels. In addition, the implementation of scripted triggers introduces the player not only to a series of surprise attacks from the monstrous baddies, but to other NPCS (Non-Player Characters) who present further information that is crucial to the 
Screenshot from Dоом 3 (id Software, 2004)

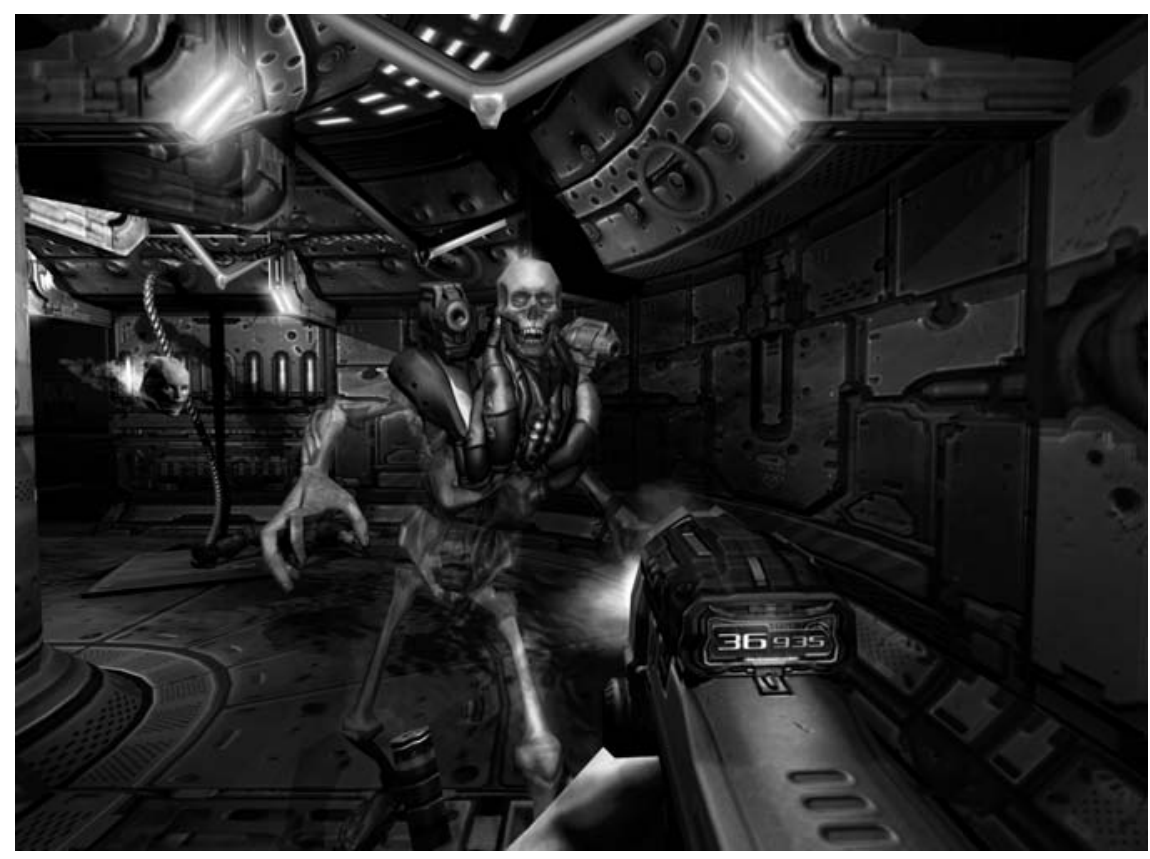

mayhem that surround the marine. All this aside, it is on the level of effects that the innovations of this game emerge.

Dоом 3 is without doubt one of the most realistic and visually astounding games ever produced. The graphics approach the quality of a pre-rendered computer graphic movie, with the result that the atmosphere of this game leaves DоOм 2 of I994, and many games produced since then - HAlo (Gearbox, 2003), half-Life (Sierra, I998), and the tom b RAider (Core Design, ig96 -2003) and GRAND THEFT AUTO (Rockstar Games, I998-2004) series - miles behind in terms of the quality of audio-visual effects. With its release, роо м 3 has set a new standard for the look of 3D games. John Carmack of id Software not only created a graphics engine from scratch but a sound engine was also implemented in the production of роом 3. In addition, to introducing Dolby 5.I, 6-channel surround-sound into its space (which not only adds to the drama but creates an off-screen space that directs players to the placement of enemies), Carmack has also created real-time dynamic lighting and shadow effects that, when experienced in gameplay, can generate some very serious scare effects. Objects not only cast shadows, but those shadows shift and change according to the light that is directed towards them.

Once Hell is unleashed, the lights in the military base go haywire. In some rooms and along corridors the lights strobe on and off intermittently, creating pockets of eerie darkness that generate intense levels of suspense and horror in the player. Armed with a flashlight (one of the new additions to the роом 3 
marine's supplies) the player navigates the labyrinthine space, aiming her torch into areas of darkness: this very action of attempted control over the chaotic space, however, also evokes dread in that it carries with it the possibility of illuminating what lies in the shadows in wait for the living. And what lies in the shadows? Sure, they are the same demons found in the first two games - imps, Pinky Demons, Hell Knights, Cacodemons, and Revenant - but now they have undergone some serious cosmetic surgery. The level of detail in each creature is a technological feat: all of the creatures have a variety of skins and features, as well as an array of distinctive screams, moans, and cries.

A description of the feeling of immersion experienced while playing this game could not do it justice. But let me try anyway. With my surround sound system blaring around me, as my marine alter-ego and I crept through the shadows of a corridor early on in the game exploring the spooky shadows with the flashlight (and ready to switch over to one of the very cool weapons) I could hear screams and whispers coming from all around me. The cries of victims, and the taunting voices of demons murmuring 'Over here' or 'Your soul is mine' - and sometimes it felt as if they were whispering in my ear. Imagine my state when, after completing a ninety-degree sweep of a corridor with the flashlight, I turned to find myself virtual face to virtual face with one mean and horrible jawless zombie. He lunged at me and I hit him over the head with the torch while hysterically telling another part of my brain (the bit that deals with rational functions) to arm myself with the shotgun. The rational part kicked into action and my shotgun sent his body every which way, splattering bits of flesh into a multitude of gory, yucky pieces.

I was reminded of the time I visited the live action ALI E N WARS (based on the films) which used to operate underneath Leicester Square in London. Entering a labyrinth underground, marines commandeered participants around a scientific installation that was breeding Aliens. Of course, the Aliens escaped and visitors were chased through the corridors by men in Alien suits. Aided by the dark environment, flashing lights, smoke, and sound effects it was very easy to shift over to the realm of disbelief and become immersed in the event. At one stage I was cornered by an Alien and my first thought was 'Oh my God, it's going to spray acid on my face'. My second thought was 'This is pretend, calm down'. It wasn't the voice of reason that won me over, however, so I grabbed the Alien and threw its body against a wall. To this day I think back on this action with embarrassment: that poor guy in the alien suit would have been nursing his bruises for days afterwards. Like my experience at ALIEN WARS, playing DOOM 3 evokes a similar kind of response. I know that the events I see before me are not real, and yet my senses respond to them as if they are. What games like Doo 3 can do so well is immerse the player into their representational spaces, while also encouraging the player to recall ро ом and роом 2's prior attempts in creating a similar aesthetic experience. For the player, there is no comparison. D o o 3 has outdone its predecessors. In the sensorial assault that ensues, the player is invited to 
believe that the illusion they witness is perceptually real. As Tom Gunning observes in relation to the pre-cinematic technologies: 'These optical entertainments exemplify the state of suspended disbelief that [French psychoanalyst] Octave Mannoni describes as "I know very well, and all the same..."'.

An assumption often made by critics who focus on what is perceived as the 'problem' of game design's 'cinema envy' is that it is not the cinema as such that is being emulated or envied: it is the realist effect that the cinema can produce. Stephen Prince has made an important point, however, in relation to the use of digital effects in the cinema - and this is equally applicable to games. Theory fails to account for the paradox that, while images may be perceptually realistic, they are referentially unreal. ${ }^{17}$ In this case, representational reality does not seek to create a world of resemblance. As Tuve has explained in a different context, 'imitation' is not necessarily about the relationship between art and reality; the issue of representation is not significant in the sense of its capacity to reproduce material reality. ${ }^{18}$ Rather, imitation and representation evoke alternate 'realities' that reflect the ability of the effects to trigger emotional responses and almost instinctive reactions from the player. Existing reality is devalued in favour of an effects space that incites the senses into full response. To 'represent' does not mean to 'stand for the reality or concept behind it'; its ultimate concern is with of the abstract nature of the senses. The senses are playfully deceived.

The virtuosity for a game like роом 3 comes from flaunting its capacity to audio-visually present constructions that have no parallel basis in the real world, yet which temporarily confront the player with the possibility that zombies and the Mancubus may really do us major bodily harm. It is the means to the deception (the technology) that is important. Like Dоом $2,{ }^{\text {I9 }}$ Dо० 3 responds to the game's historical context, specifically, its relationship to the first two games and to other id Software productions, including the famous QUAKE series. The story Dоом 3 has to tell us is one that critically engages with issues of originality, 'creative process' and technological advancement in gaming culture.

\section{id Software and technological milestones}

Fantastic effects pave the way for technological advancement. The effects and experiences produced by games like Doom 3 do not only display virtuosity with regard to the way they tap into and reframe media history, they also tell a crucial story about the technological history of game development. This objective is nothing new to the games produced by id Software. The games of this company obsessively display a self-reflexive attitude to the creative process that is reliant upon the relationship between past and present. In addition to placing themselves within the context of media history, on a formal level, id Software has always been obsessed with also telling players a 'paradigmatic' story about its place within the history of game technology. Each of the games released by 


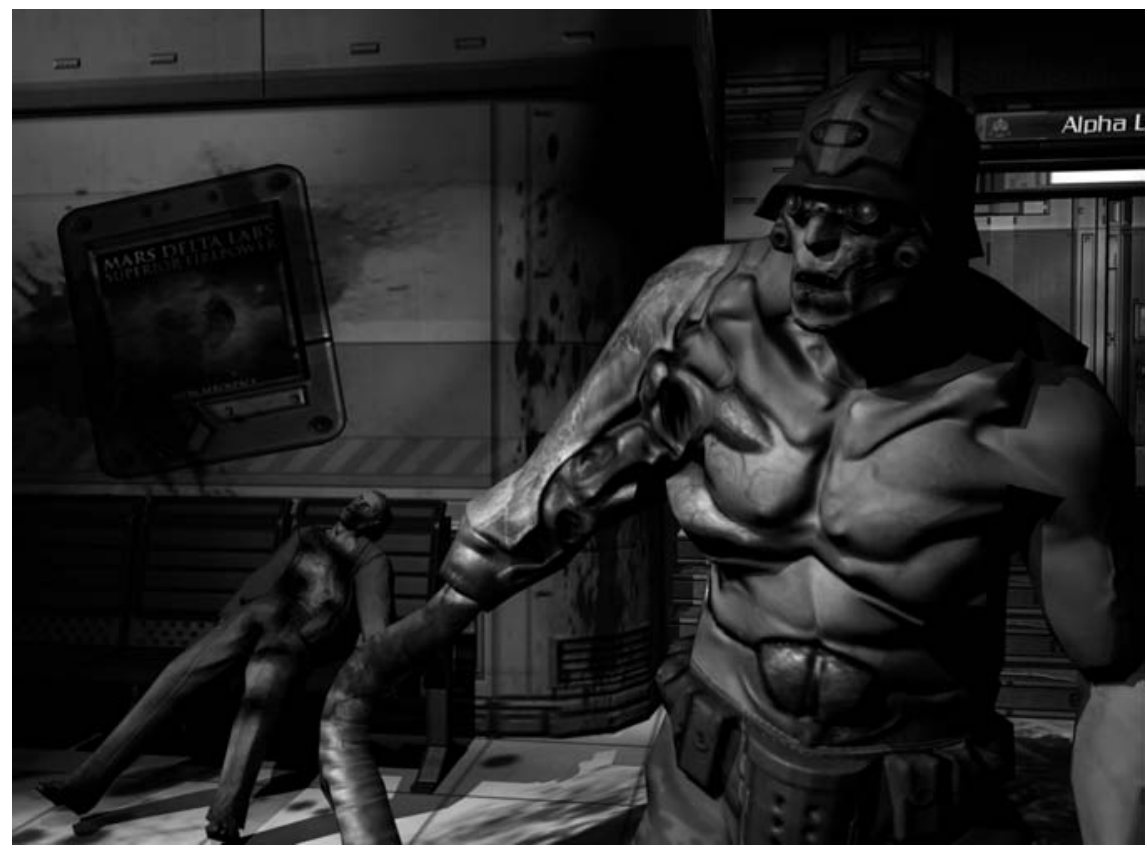

id Software has set new benchmarks for game developers and the computer systems that gamers use to play their games. Not only have gamers continued to marvel at the amazing graphics and engines of id games, but often the technological demands of most id-games have resulted in technological shifts: the high end requirements of computer hardware have literally encouraged the consumer's shift to more advanced PC-systems. id Software's penchant for pushing the boundaries and striving towards extending the game market and experience was evident in WOLFENSTEIN 3D (I992), which transformed the two-dimensional platform game into a separate genre known as the shoot 'em up genre. Rather than moving characters across a series of platforms that ran parallel to the screen, the player manoeuvred them through a series of corridors that stressed movement into the simulated depth of the computer screen space. John Carmack and John Romero included texture mapping, which made possible more realistic textures to surfaces. In turn, wO LF E N STE I N 3D's advanced graphics engine and memory requirements became important in showcasing Intel's next generation Pentium chip.

Doom (I993) extended woLFENSTEIN 3D's advances further still: one year after its release, the previously realistic 3D space of wO LFENSTE IN 3D suddenly became a cartoonish, two-dimensional articulation of a three-dimensional space. In light of Doom's (and, in I994, Doom 2's) more detailed and colourful environments and characters, WOLFENSTEIN 3D seemed to offer a monotonous environment. With the introduction of more advanced texture mapping and the addition of diminished lighting, D оо м provided hue variations that aided the 
illusion of shadows and recession into space. Not only did D о м make possible a more convincing and atmospheric immersion into the game space, but it was also pivotal in broadening the conventions and expectations of the shoot 'em up genre. Doом became the form that all shoot 'em ups would aspire to. Carmack and Romero designed Doom with vga (Video Graphics Adapter) cards in mind. Hitting the market in I987, the vGA-cards had greater graphics capabilities and superseded the EGA (Enchanced Graphics Adapter) cards, which were first released in I984. In much the same way, in I990, id had insisted on working with the most current graphics advances: they designed COM MAN DER KEEN aS a game best played on the new EGA-cards, rather than the CGA (Computer Graphics Adapter) which was, by I990, old technology. In privileging the most current developments in graphics card capabilities and hardware, Carmack ensured that id's games would represent the technological cutting edge. Discussing Dоом, one game reviewer explained that the release of this game actually encouraged individuals to replace their computers with the 'shiny new 486 sx / Dx just to play the game'. Being far more capable of handling the memory requirements of Dоo , the earlier 286 and 386 PC-models were abandoned for the 486 which had a more powerful microprocessor. Again, in favouring the technological cutting edge, id Software also supported a shift in the computer industry's hardware advances. ${ }^{20}$ Doом 2 then developed on this further still.

QuAKE (I996), another First-Person Shooter, expanded the boundaries of the genre by incorporating new features still, adding an even greater realism and more intensive form of game play by shifting a significant role of the graphics from the central processing unit (CPU) to the graphics card. In freeing up the CPU, which is the part of the computer that carries out the commands of software (such as games), the game could not only run more smoothly, but its effects could be even more impressive compared to those of the Doom duo. In addition, graphics and sound effects became high resolution and even more detailed, and the character movement included greater mobility: aside from walking, running and turning heroes could now also look up and down, jump, swim and crouch. As Kushner explains, ${ }^{2 \mathrm{I}}$ computer games have driven the evolution of video cards, and QUAKE was integral to the next stage in the evolution. Its primary innovation centered on light mapping and the production of realtime light sources, which more effectively created the illusion of threedimensionality and perspective. However, in order to play QUAKE effectively, previously cutting edge computer technology was relegated to history: the $486 \mathrm{~s}$ that had run Dоом and Dоом 2 could no longer do QUAKE's graphics justice. New history was being made and the new Pentium chips became the technology to have. To quote a reviewer: 'QUAKE soon became the de facto benchmark for the consumer graphics card industry'. ${ }^{22}$ With each game id released, the company also sought to produce the technological cutting edge, in the process creating a dialogue with history. Developing on the popularity of the Dоoм game 


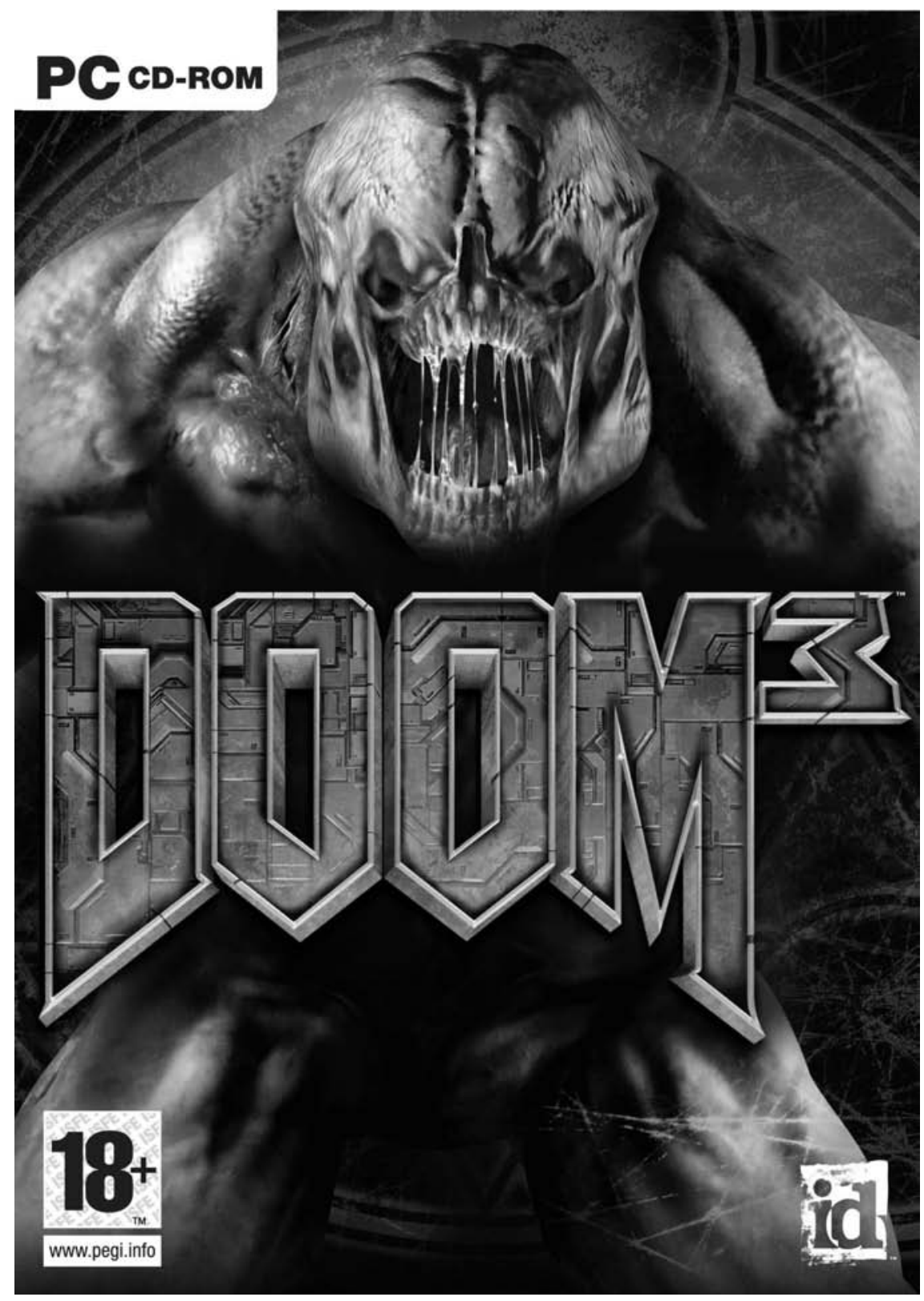

Packshot Doom 3 (id Software, 2004)

death matches, QUAKE advanced on this through network gaming - its revolutionary effects are still felt today in multiplayer gaming. In addition, developing on the modification possibilities introduced by the first two Dоом games, John Carmack's programming code was made available to players in the game itself, with the result that gamers and developers could modify the QUAKE engine: the environment, Non-Player Characters, objects could be changed to suit their own 
requirements. Since the licensing of the Quake source code in I999, and 'improvements' that followed with the release of QUAKE II and QUAKE II I ARENA, the QUAKE engine has become the programming foundation for many games, including RETURN TO THE CASTLE WOLFENSTEIN (id Software, 2003), AMERICAN MCGEE'S ALICE (Electronic Arts, 2000), JEDI KNIGHT II: JEDI OUTCAST (Raven Software, 2000), STAR TREK VOYAgER ELITE FORCE (Raven Software, 2000) and MEDAL OF HONOR: ALLIED ASSAULT (2002). ${ }^{23}$ The possibility of game modification introduced with the QUAKE engine has also been instrumental in triggering the MACH IN IMA ${ }^{24}$ phenomenon that allows the productions of films made in game engines - the most successful of these without doubt being the Red vs. Blue series that is based on the HALo games (which, influenced by the premise of the QUAKE engine, produced the HALO engine). ${ }^{25}$ The release of QUAKE IV (and its radically redefined engine some time in the not to distant future) promises to keep changing game history.

Then до о 3 was released, and the possibilities inherent in the Dо о 3 engine have not even been tapped into yet. A separate sound code has been written which, as discussed above, introduces a layered complexity that is convincingly realistic-especially in the context of the surround sound system that is intended to support it. Above all, the sound produces a spatial realism that has not been experienced before in game design. The new rendering engine written by Carmack includes the innovation of bump-maps, which, as their name implies, produces greater texture on surfaces (and related lighting effects): steel surfaces have the sleek texture of steel, skin has the texture we associate with flesh (from healthy to rotting flesh), the smoke that erupts from pipes in the base has the ephemeral consistency of smoke, and so on. Drawing upon the animation skills of Fred Nilsson (animator of the 200I DreamWorks box office hit S H REK) - and thanks to the advance 3D engine created for the game -3D modeling software like Maya has been used more effectively to create impressive cinematic animation effects. Add to this the real-time lighting and shadow effects, and it is not difficult to imagine PC gamers running out to their local computer shop to upgrade their systems or to replace their PCS with new systems that can do justice to the game.

In May 2003, before the release of Doom 3, Kyle Bennett of the online gaming service Hardoср benchmarked роом 3 using the most recent ATI and NVIDiA graphics cards. NvidiA's GeForcefx 5900 outrun the main competition offered by the company ATI. Significantly, Bennett makes a crucial point about the way game software technologies (such as that of Doo M 3) can drive the future direction of computer companies and the hardware technologies that they develop. He explains that 'Do o 3 is likely to have more impact on the gaming and hardware industries overall than any other game to come in the next decade, as it is surely one of those quantum leaps in technology that are becoming so rare. Nvi D I A is obviously aware of this and doing everything they can to be 
the DOOM 3 video card. ${ }^{26}$ Not only do individual games like Doo M 3 and game companies like id Software engage is a game about virtuosity, but computer companies also can not resist the exhibitionist showcasing of their technology. In the case of NVID IA, D o M 3 becomes the vehicle of the corporation's technological virtuosity: the game displays NVIDIA superiority and mastery over the products of competing companies like ATI.

In short, by pushing the envelope in terms of game effects and therefore altering game history, companies like id Software also encourage the invention and implementation of new hardware technology within the computer industry. They create both game and game technology's future. In turn, this technological innovation relegates older technology into its place in history. In this case, a further meta-text is introduced into Collins' example of the function on the paradigmatic axis: this story is one about the realities of commerce, industry and their history.

Entertainment forms like computer games have increasingly displayed a concern for engulfing and engaging the spectator actively in games that are concerned with their own remediated and media-specific sensory and playful experiences. The main focus of such spectacle is to conjure wondrous and sensorially invasive illusions that both immerse us in their representational spaces (a process that Bolter and Grusin label immediacy), and also expose the processes of the technological mediation (which Bolter and Grusin call hypermediacy). Perhaps more than other entertainment forms, computer games perform and compete with inter- and intra-media effects traditions, continually attempting to technically out-perform these effects technologies - and the perceptions of reality that these technologies delivered. In their efforts to remediate themselves, computer games often display a virtuosity and theatricality that can not resist exposing the technology that drives them. Framing itself within its own media history, therefore, games like роом 3 and others produced by companies like id Software, invade the player's space in deceptively real and immediately experiential ways. This spectacle is, however, also displayed in order that the player may admire it as a multi-technological feat of game technology. The experiences that games articulate, flaunt their capacity for making a reality out of an illusion - or, rather, for making the fantastic enter our world in such immediate and sensorially invasive ways. Who can say what new feat the technology that drives these game worlds will produce in the future? For the time being, to paraphrase Ash from the third Evil DEAD film, ARMy of DARKNess (Sam Raimi, I993), 'All, hail to the King! Doom is back'. 
I 'Violence is Golden', PC Gamer, vol. I, no. 4, I994, p. 43.

2 Alfred Hermida, 'Long-awaited Doom 3 leaked online', available at http://www.filmrot.com/ geeklinks/0049I8.php.

3 Jay David Bolter \& Richard Grusin, Remediation: Understanding New Media, Cambridge, Massachusetts I999.

4 Angela Ndalianis, Neo-Baroque Aesthetics and Contemporary Entertainment, Cambridge, Massachusetts 2004 .

5 The Medal OF HONOR series, for example, was based on the Spielberg-directed film SAvin G PRIVATE RYAN (1998). The film was jointly produced by Amblin Entertainment (Spielberg's solo company), DreamWorks s KG (Spielberg's partner company with Katzenberg and Geffen), and Paramount Pictures Corporation. Owning partial rights to this franchise, DreamWorks developed MEDAL OF HONOR: FRONTLINE for PS2, and commissioned the game company Electronic Arts to publish the game. In such an exchange, the logic assumes that viewers of the film may then be interested in the game, while gamers may be drawn to the film.

6 Justin Wyatt, High Concept: Movies and Marketing in Hollywood. Austin I994, p. I60.

7 Bolter \& Grusin, Remediation, p. I5.

8 For max payn E, see Galen Davis, Game Noir: the Construction of Virtual Subjectivity in Computer Gaming, Stanford 2002, available at http://www.gamasutra.com/education/theses/2002082I/ davis.pdf.

9 Jim Collins, 'Batman: The Movie, Narrative: The Hyperconscious'. In: Roberta E. Pearson \& William Uricchio (eds), The Many Lives of the Batman: Critical Approaches to a Superhero and His Media. New York I99I, p. I68.

ıo Collins, 'Batman: The Movie', p. I69.

II Idem, p. I73.

I2 The characters CthuIhu, Azathoth, Dagon, Shub-Niggurath, Elder Beings, Hastur and the Night-gaunts were all creatures that initiated the Cthulhu mythology by making appearances, initially in the 1928 story 'The Call of Cthulhu' (published in the pulp magazine series Weird Tales, which was first published in I924), and later in other tales that included 'The Temple', 'Dreams of the Witch-House', 'The Haunter in the Dark', 'The Shadow out of Time', and 'The Shadow over Innsmouth'. See 'Call of Cthulhu.' Available athttp://members.tripod.com/ Tiras/deityoro.html.

I3 Erik Davis, 'Calling Cthulhu H.P. Lovecraft's Magick Realism,' I995. Available at http:// www.levity.com/figment/lovecraft.html. Originally published as 'Calling Cthulhu', in: Gnosis (Fall) I995.

I4 James Bregman, 'Reaping the profits of Doom'. Available at: http://news.bbc.co.uk/I/hi/ technology/3559624.stm.

I5 Wylie Sypher, Rococo to Cubism in Art and Literature. New York I960, p. xxiv.

I6 Tom Gunning, 'Animated Pictures”, Tales of Cinema's Forgotten Future,' Michigan Quarterly Review, vol. 34, no. 4, p. 47I.

I7 Stephen Prince, 'True Lies: Perceptual Realism, Digital Images, and Film Theory,' Film Quarterly, vol. 49, no 3, I996, p. 36.

I8 Rosemond Tuve, Elizabethan and Metaphysical Imagery; Renaissance Poetic and TwentiethCentury Critics. Chicago I947, p. I3.

I9 Angela Ndalianis, 'The Rules of the Game: Evil Dead II ... Meet thy Doom', In: H. Jenkins, T. McPherson, J. Shattuc (eds), Hop on Pop: the Politics and Pleasures of Popular Cultures, Durham 2003.

20 Zaldron, 'Doom 3 Technology'. Available at: http://www.Doomworld.com/lordflathead/ zalrdon.html. For an overview of some of Dоo м 3's technological innovations, also see David Kushner 'The Wizardry of Id', Spectrum Online, 22 September 2004. Available at: http://www.spectrum. ieee.org/w в воn Ly/publicfeature/augo2/id.html; and Kyle Bennett \& Brent Justice, 'The Official Doom $3[\mathrm{H}]$ ardware Guide', July 29, 2004. Available at http://www.hardocp.com/articleprint. html?article_id=644. 
2I Kushner, 'The Wizardry of Id', n.p.

22 Zaldron, 'Doom 3 Technology', n.p.

23 See: http://www.campusprogram.com/reference/en/wikipedia for the mentioned games.

24 See: http://www.campusprogram.com/reference/en/wikipedia.

25 The Red vs. Blue site is available at: http://www.redvsblue.com/.

26 Kyle Bennett, 'Doom 3 Benchmarks', [H]ard/OCP. Available at: http://www.hardocp.com/ article.html?art=N Dco. 